\title{
Gene expression analysis of endobronchial epithelial lining fluid in the evaluation of indeterminate pulmonary nodules
}

\author{
Nicolas Kahn, MD, ${ }^{\mathrm{a} *}$ Ruprecht Kuner, $\mathrm{PhD},{ }^{\mathrm{e} *}$ Ralf Eberhardt, MD, PhD, ${ }^{\mathrm{b}}$ Michael Meister, $\mathrm{PhD},{ }^{\mathrm{c}}$ \\ Thomas Muley, PhD,${ }^{\mathrm{c}}$ Susanne Winteroll, MD, PhD, ${ }^{\mathrm{d}}$ Philipp A. Schnabel, Prof, ${ }^{\mathrm{f}}$ Akitoshi Ishizaka, Prof, ${ }^{\mathrm{g}}$ \\ Felix J. F. Herth, Prof, ${ }^{\mathrm{b}}$ Annemarie Poustka, Prof, ${ }^{\mathrm{e}}$ Holger Sültmann, PhD, ${ }^{\mathrm{e}}{ }^{*}$ and Hans Hoffmann, Prof ${ }^{\mathrm{a} *}$
}

\begin{abstract}
Objective: Making a definitive preoperative diagnosis in patients with indeterminate pulmonary nodules is still a challenge. Gene expression profiling may be a useful adjunctive diagnostic utility in this regard. We investigated the feasibility of bronchoscopic microsampling to collect endobronchial epithelial lining fluid to obtain RNA as a starting point for gene expression profiling.
\end{abstract}

\begin{abstract}
Methods: In 15 patients, epithelial lining fluid was collected in triplicate from subsegmental bronchi close to the pulmonary nodules and from contralateral lungs. Diagnosis was confirmed by transbronchial biopsy or surgery (non-small cell lung cancer, $n=11$; benign or other lesions, $n=4$ ). Total RNA was isolated from the samples and evaluated concerning quantity and quality. The complementary DNA was generated and analyzed by quantitative real-time polymerase chain reaction for potential lung cancer associated genes like matrix metalloprotinase (MMP9).
\end{abstract}

Results: Total RNA of adequate amount ( $>0.8 \mu \mathrm{g})$ and sufficient quality was obtained in $13(86 \%)$ of the 15 patients. In patients with lung cancer, normalized $M M P 9$ gene expression levels in endobronchial lining fluid samples collected close to the lesions were in median 12 times higher than levels in the matching contralateral samples. $M M P 9$ expression levels were particularly high in endobronchial lining fluid samples collected from patients with squamous cell carcinoma but not elevated in the case of benign lesions.

Conclusions: Our results show that quantitative gene expression analysis of endobronchial lining fluid collected by bronchoscopic microsampling is both feasible and reliable and may therefore be a useful additional diagnostic method in patients with indeterminate pulmonary nodules.

Making a definitive preoperative diagnosis in patients with indeterminate pulmonary nodules is still a challenge in clinical practice. Identification of malignant nodules is important because they represent a potentially curable form of lung cancer. ${ }^{1}$ The prevalence of malignancy in patients with solitary pulmonary nodules varies widely across studies. In different lung cancer screening studies the prevalence of malignancy ranged from $2 \%$ to $13 \%$. $^{2}$ Surgery is the diagnostic "gold standard" and the definitive treatment for malignant nodules, but surgery should be avoided in patients

From the Departments of Thoracic Surgery ${ }^{a}$ and Pneumology and Critical Care Medicine, ${ }^{\mathrm{b}}$ the Translational Research Unit, ${ }^{\mathrm{c}}$ the Division of Clinical Chemistry and Microbiology, ${ }^{\mathrm{d}}$ Thoraxklinik, University of Heidelberg, Germany; the Division of Molecular Genome Analysis, German Cancer Research Center, ${ }^{\mathrm{e}}$ Heidelberg, Germany; the Institute of Pathology, ${ }^{\mathrm{f}}$ University of Heidelberg, Germany; and the Division of Pulmonary Medicine, Department of Medicine, ${ }^{\mathrm{g}}$ Keio University School of Medicine, Tokyo, Japan.

This study was supported by a grant of the German Federal Ministry for Education and Research supporting the German National Genome Research Network (NGFN grant 01GR0418) and intramural grants of the DKFZ and the Thoraxklinik.

* N. Kahn, R. Kuner, H. Sültmann, and H. Hoffmann contributed equally to the work.

Received for publication Dec 22, 2008; revisions received March 12, 2009; accepted for publication April 23, 2009.

Address for reprints: Ruprecht Kuner, PhD, Division of Molecular Genome Analysis, German Cancer Research Center, Im Neuenheimer Feld 580, 69120 Heidelberg,

Germany (E-mail: r.kuner@dkfz.de).

J Thorac Cardiovasc Surg 2009;138:474-9

$0022-5223 / \$ 36.00$

Copyright (c) 2009 by The American Association for Thoracic Surgery doi: $10.1016 /$ j.jtcvs.2009.04.024 with benign nodules. Biopsy often establishes a specific benign or malignant diagnosis, but biopsy is invasive, potentially risky, and frequently nondiagnostic. ${ }^{1}$

It is evident that tumor cells manipulate their environment with respect to cell-cell and cell-extracellular matrix interactions, angiogenesis, and inflammation. ${ }^{3}$ Our preclinical study is based on the hypothesis that the adjacent tissue of an indeterminate pulmonary nodule harbors the potential to reveal the presence of tumor cells. We investigated whether gene expression profiling of RNA derived from endobronchial epithelial lining fluid (ELF) collected by bronchoscopic microsampling may be a useful adjunctive diagnostic method in the evaluation of patients with pulmonary nodules.

\section{PATIENTS AND METHODS \\ Patient Characteristics}

This pilot study included 15 patients (Table 1) with indeterminate solitary pulmonary nodules who were scheduled to undergo diagnostic bronchoscopy at the Thoraxklinik Heidelberg between January and June 2007. The institutional review board approved the data collection and analysis, and written informed consent was obtained from all patients before the procedure. In all cases definitive histologic diagnosis was established either by transbronchial biopsy or by subsequent surgical resection (adenocarcinoma, $\mathrm{n}=7$; squamous cell carcinoma, $\mathrm{n}=4$; small cell lung cancer, $\mathrm{n}=1$; non-Hodgkin lymphoma, $\mathrm{n}=1$; and benign nodule, $\mathrm{n}=2$ ). 


\section{Abbreviations and Acronyms \\ $B 2 M \quad=$ beta-2-microglobulin \\ BMS = bronchoscopic microsampling \\ CEA $=$ carcinoembryonic antigen \\ ELF = endobronchial lining fluid \\ $E S D=$ esterase $\mathrm{D}$ \\ $\mathrm{MMP}=$ matrix metalloprotinase \\ NSCLC = non-small cell lung cancer \\ qRT-PCR $=$ quantitative real-time polymerase chain reaction}

\section{Bronchoscopic Microsampling}

Bronchoscopic procedures were performed under general anesthesia or conscious sedation in standard fashion. A variety of videobronchoscopes (models BF T160; Olympus; Tokyo, Japan) were used. After complete inspection of the bronchial tree including the subsegmental bronchi, fluoroscopy was performed and the bronchoscope was navigated next to the lesion. While navigating, we placed a standard transbronchial biopsy catheter in the working channel to avoid contamination of the channel (and subsequently the sampling catheter) with ELF or blood. ELF was sampled with the Olympus (Tokyo, Japan) mucus collection probe $\mathrm{BC}-401 \mathrm{C} / \mathrm{BC} 402 \mathrm{C}$ (probe diameter $1.9 \mathrm{~mm}$, probe length $20 \mathrm{~mm}$ ) (Figure 1, $B$ and $C$ ). The bronchoscopic microsampling (BMS) device was inserted through a guided sheath into the bronchi close to the nodule or at the contralateral site, positioned fluoroscopically. The cotton-like tip of the collection probe device was unsheathed and left for 10 seconds within $20 \mathrm{~mm}$ of the lesion (or within a bronchus of the contralateral site). During this deployment time, the BMS device was not further manipulated after positioning, to allow adsorption of the lining fluid at that location. Subsequently, the ELF-containing tip was withdrawn into the sheath of the collection probe, and both devices were simultaneously retrieved from the lung. Immediately after retrieval of the BMS device, the tip containing the absorbed ELF was sectioned at the end of the stainless steel guide wire $2 \mathrm{~cm}$ from its end with sterile scissors, placed into a reaction tube, and shock-frozen in liquid nitrogen to avoid RNA degradation. The probes were subsequently kept at $-80^{\circ} \mathrm{C}$ until further processing. In each patient, BMS procedures were repeated in triplicate at the site of the lesion and from the contralateral lung (corresponding subsegmental bronchus) as internal control. An overview of the procedure is given in Figure 1, A.

\section{Cytospin Preparation}

From 2 patients, ELF samples were collected next to the lesion $(n=6)$ and from the contralateral lung $(n=6)$. The samples were diluted with 350 $\mu \mathrm{L}$ of saline and cytocentrifuged at $1500 \mathrm{rpm}$ for 10 minutes in a Shandon Cytospin 3 cytocentrifuge (Shandon, Inc, Pittsburgh, Pa). The preparations were May-Grunwald-Giemsa stained and analyzed by light microscopy.

\section{Total RNA Extraction}

The catheters were discarded after lysis with denaturing guanidine isothiocyanate-containing buffer. Total RNA extraction was performed with RNeasy Micro Kit (Qiagen, Hilden, Germany) according to the manufacturer's instructions. The quantity of total RNA was measured by spectrophotometer (NanoDrop Technologies, Wilmington, Del). The quality of total RNAs was assessed with Agilent 2100 Bioanalyzer and Agilent RNA 6000 Pico Kit (Agilent Technologies GmbH, Waldbronn, Germany). From each patient, one ELF sample pair (lesion and contralateral site), which yielded quality RNA (28S/18S rRNA larger than 1.0), was used for further experiments.

\section{Quantitative Real-Time Polymerase Chain Reaction (qRT-PCR)}

Reverse transcription was performed with $200 \mathrm{ng}$ total RNA per reaction using RevertAid First Strand cDNA Synthesis Kit (Fermentas, Burlington, Ontario, Canada). Expression analysis of 9 genes was performed with 26 different specimens including matched indeterminate pulmonary nodule and contralateral microsampling extracts of the same patients by qRTPCR (ABI Prism 7900HT Sequence Detection System; Applied Biosystems, Weiterstadt, Germany). We applied gene-specific primers and probe Taqman assays (ABI) and performed a relative quantification of all genes by using two housekeeping genes, esterase $\mathrm{D}(E S D)$, which is reported to be a suitable internal control in lung tissues, and beta-2-microglobulin $(B 2 M) . B 2 M$ is often used for this purpose in peripheral mononuclear blood

TABLE 1. Patient and nodule characteristics and total RNA quantity and quality on ELF sample preparation

\begin{tabular}{|c|c|c|c|c|c|c|c|c|c|}
\hline Pt. no. & $\begin{array}{l}\text { Age } \\
(\mathbf{y})\end{array}$ & Gender & $\begin{array}{c}\text { Smoking } \\
\text { history } \\
\text { (pack-years) }\end{array}$ & $\begin{array}{r}\text { Histologic } \\
\text { diagnosis }\end{array}$ & $\begin{array}{c}\text { Tumor } \\
\text { size }(\mathbf{m m})\end{array}$ & Tumor location & $\begin{array}{c}\text { Lesion } \\
\text { total RNA } \\
(\mu \mathrm{g}) \\
\end{array}$ & $\begin{array}{c}\text { CL total } \\
\text { RNA } \\
(\mu \mathrm{g}) \\
\end{array}$ & $\begin{array}{l}\text { RNA quality } \\
28 S / 18 S>1.0\end{array}$ \\
\hline 1 & 65 & M & 80 & SCC & $45 \times 40$ & Right upper lobe & 1.74 & 1.09 & Yes \\
\hline 2 & 57 & $\mathrm{~F}$ & 0 & NHL & $170 \times 130$ & Right upper lobe & 1.32 & 1.57 & Yes \\
\hline 3 & 58 & $\mathrm{~F}$ & 15 & $\mathrm{AC}$ & $45 \times 35$ & Right lower lobe & 1.33 & 1.49 & Yes \\
\hline 4 & 69 & F & 45 & $\mathrm{AC}$ & $35 \times 15$ & Left upper lobe & 1.57 & 2.24 & Yes \\
\hline 5 & 59 & M & 45 & SCC & $50 \times 45$ & Right lower lobe & 1.44 & 1.04 & Yes \\
\hline 6 & 62 & $\mathrm{~F}$ & 0 & $\mathrm{AC}$ & $30 \times 20$ & Left upper lobe & 1.44 & 1.31 & Yes \\
\hline 7 & 60 & M & 50 & $\mathrm{AC}$ & $30 \times 30$ & Right lower lobe & 1.05 & 1.58 & Yes \\
\hline 8 & 79 & $\mathrm{~F}$ & 0 & $\mathrm{AC}$ & $52 \times 37$ & Left lower lobe & 1.03 & 1.78 & Yes \\
\hline 9 & 63 & M & 30 & $\mathrm{AC}$ & $30 \times 20$ & Left upper lobe & 1.66 & 1.09 & Failed \\
\hline 10 & 57 & M & 80 & SCLC & $25 \times 30$ & Left upper lobe & 1.74 & 0.97 & Yes \\
\hline 11 & 69 & M & 30 & $\mathrm{SCC}$ & $45 \times 40$ & Left lower lobe & 1.43 & 1.64 & Yes \\
\hline 12 & 72 & M & 30 & Benign & $25 \times 25$ & Left upper lobe & 0.93 & 1.10 & Yes \\
\hline 13 & 64 & M & 30 & Benign & $35 \times 20$ & Right upper lobe & 0.86 & 1.59 & Yes \\
\hline 14 & 76 & M & 30 & SCC & $55 \times 50$ & Right lower lobe & 1.13 & 0.98 & Yes \\
\hline 15 & 59 & M & 40 & $\mathrm{AC}$ & $30 \times 20$ & Right upper lobe & 0.60 & 0.49 & Failed \\
\hline
\end{tabular}

Endobronchial lining fluid; lesion, ELF next to the indetem $N H L$, non-Hodgkin lymphoma; $S C L C$, small cell lung cancer. 

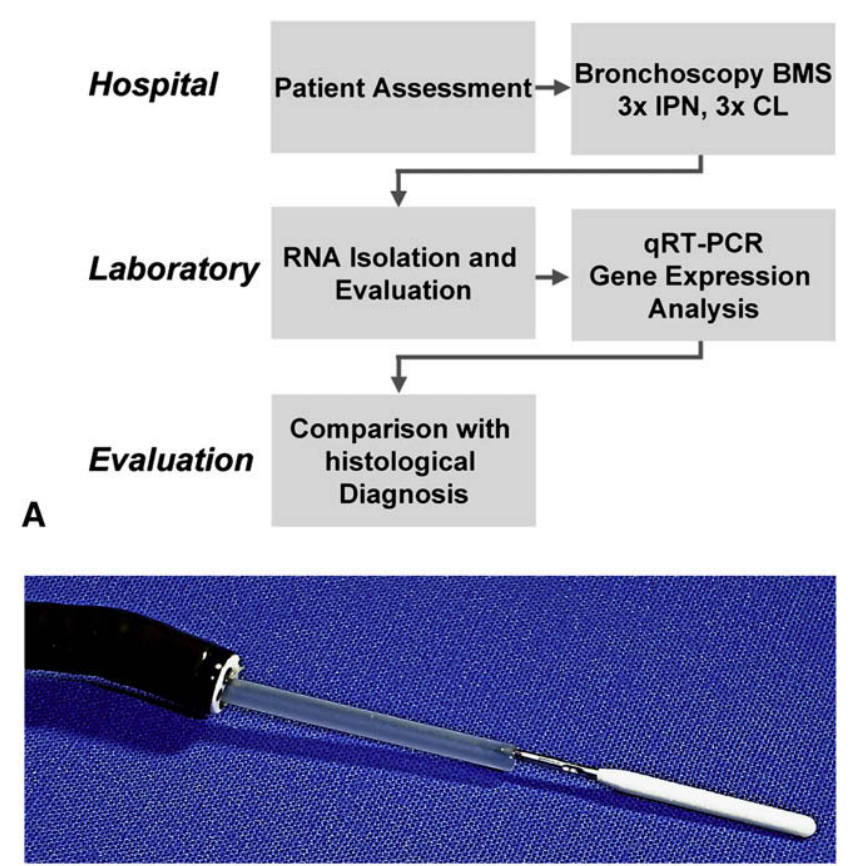

B

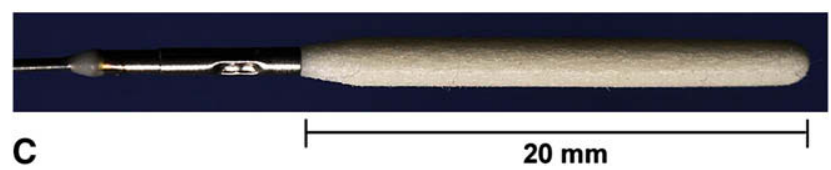

FIGURE 1. A, Procedure flow chart of gene expression profiling from endobronchial epithelial lining fluid (ELF) collected by bronchoscopic microsampling (BMS) next to the intermediate pulmonary nodules (IPN) and from the contralateral lung $(C L)$ in patients with IPN. B, Image of the end of the videobronchoscope (model BF T160, Olympus; Tokyo, Japan) including the sheath of the Olympus Mucus Collection Probe BC-402C with the tip in deployed position. C, The Olympus Mucus Collection Probe $\mathrm{BC} 402 \mathrm{C}$ (probe diameter $1.9 \mathrm{~mm}$, probe length $20 \mathrm{~mm}$ ) in more detail.

cells that may be a component of ELF samples. The accuracy of measurements for all samples was optimized by using technical triplicates from each sample. The qRT-PCR method and analysis were described in detail in our previous study. ${ }^{4}$ Gene expression differences between indeterminate pulmonary nodule and contralateral microsampling extracts were analyzed by a paired $t$ test. Genes were regarded to be differentially expressed using cutoff criteria of a $P$ value $<.05$ and a linear fold change $\geq 2$ or $\leq 0.5$ for each comparison. A detailed list of examined genes including nomenclature, National Center for Biotechnology Information Entrez Gene ID, representative sequences of primer, and probe Taqman assays is given in Table 2.

\section{RESULTS \\ BMS}

Fifteen consecutive patients with fluoroscopically visible indeterminate solitary pulmonary nodules were examined (10 men and 5 women, median age, 69 years, range 57-79 years). The mean examination time (including subsequent transbronchial biopsy procedures) was 15 minutes (range, 10-30 minutes). No complications occurred with the BMS procedures. The characteristics of the 15 patients, including age, gender, smoking history, final histologic diagnosis, tu- mor size, and tumor location, are presented in Table 1. Differential cell counts from cytospin preparations of ELF collected by BMS revealed proportions of $50 \%$ to $80 \%$ macrophages, $10 \%$ to $30 \%$ lymphocytes, and $5 \%$ to $15 \%$ epithelial cells. No significant difference in the cell composition was observed between nodule site (with or without tumor background) and contralateral site.

\section{RNA Sample Preparation and Gene Expression Analysis}

Total RNA of adequate amount $(>0.8 \mu \mathrm{g})$ and sufficient quality was obtained from both ELF samples next to the lesion and from the contralateral lung in $13(86 \%)$ of the 15 patients. Patients 9 and 15 were excluded from further analysis because of poor quality of the total RNA retrieved. The total amount of RNA retrieved from ELF samples next to the lesion and from contralateral lung of the same subject, and results of RNA quality assessment, are presented in Table 1. Blood cell content varied across samplings but did not result in a systematic influence with respect to RNA quality or qRT-PCR measurements.

We tested the reliability of gene expression analysis in ELF samples by performing quantitative RT-PCR from known lung cancer-associated genes that display potential surrogate markers (KRT19, CEACAM3, CEACAM5, and $E G F R)$ or are involved in cell adhesion and migration processes (MMP9, TWIST1, MUCl, and CDH1).* These genes were frequently found to be differentially expressed in tumor tissue versus normal tissue on the basis of results from non-small cell lung cancer (NSCLC) gene expression profiling studies. ${ }^{4}$ All expression values were normalized using $E S D$ and $B 2 M$ as internal control genes. The investigated transcripts have been detected in $70 \%$ to $100 \%$ of all samples with lower (TWIST1, CEACAM3, KRT19, MMP9, $C D H 1$, and $E G F R)$ or higher relative expression (B2M, $M U C 1, C E A C A M 5$, and $E S D$ ) shown in Table 2. Significant differential expression was observed for $M M P 9(P=.0039)$ between ELF samples collected next to the lesion and contralateral lung samples of patients with pulmonary nodules that were finally diagnosed to be lung cancer (Figure 2; Table 3). The median expression values of $M M P 9$ in the samples collected next to the lesion were 12 -fold higher than in the contralateral lung samples. The $M M P 9$ expression was more heterogeneous in adenocarcinoma but was concordantly enhanced in patients with squamous cell carcinoma. In the samples of patients with diseases other than adenocarcinoma or squamous cell carcinoma of the lung, $M M P 9$ was either lower expressed or down-regulated in samples collected next to the lesion as compared with contralateral

\footnotetext{
* KRT19, keratin 19; CEACAM, carcinoembryonic antigen-related cell adhesion molecule; EGFR, epidermal growth factor receptor; TWIST1, twist homolog 1 (Drosphila); $M M P 9$, matrix metalloprotinase 9; $C D H 1$, cadherin 1 , type 1 , E-cadherin (epithelial); $B 2 M$, beta-2-microglobulin; $M U C 1$, mucin 1 (cell surface associated); $E S D$, esterase D.
} 
TABLE 2. Expression analysis of potential tumor-associated genes in ELF samples collected next to the lesion and from contralateral lung (CL) using qRT-PCR

\begin{tabular}{|c|c|c|c|c|c|c|c|c|}
\hline \multirow[b]{2}{*}{$\begin{array}{c}\text { Gene } \\
\text { symbol }\end{array}$} & \multirow[b]{2}{*}{$\begin{array}{c}\text { Entrez } \\
\text { gene ID }\end{array}$} & \multirow[b]{2}{*}{ Assay ID } & \multirow[b]{2}{*}{ Representative sequence } & \multicolumn{2}{|c|}{ qRT-PCR Ct value } & \multirow[b]{2}{*}{$\begin{array}{c}\text { Present } \\
\text { values }(\%)\end{array}$} & \multicolumn{2}{|c|}{ ELF lesion (NSCLC) vs CL } \\
\hline & & & & $\begin{array}{c}\text { Median } \\
\text { Ct }\end{array}$ & $\begin{array}{c}\text { Median } \\
\text { MAD }\end{array}$ & & $\begin{array}{c}P \\
\text { value }\end{array}$ & $\begin{array}{c}\text { Fold } \\
\text { change }\end{array}$ \\
\hline$M M P 9$ & 4318 & Hs00234579_m1 & AGTACCGAGAGAAAGCCTATTTCTG & 34.2 & 0.08 & 100 & .0039 & 12.52 \\
\hline TWISTI & 7291 & Hs00361186_m1 & GCCGGAGACCTAGATGTCATTGTTT & 39.2 & 0.08 & 70 & .0506 & 2.97 \\
\hline CEACAM3 & 1084 & Hs00174351_m1 & TCCATGTATACCAAGAAAATGCCCC & 37.0 & 0.15 & 81 & .2463 & 1.83 \\
\hline $\mathrm{CDH1}$ & 999 & Hs00170423_m1 & CCCGCCCCATCAGGCCTCCGTTTCT & 33.9 & 0.14 & 88 & .4077 & 0.82 \\
\hline$E G F R$ & 1956 & Hs00193306_m1 & GCAGATCGCAAAGGGCATGAACTAC & 32.0 & 0.04 & 100 & .4205 & 1.40 \\
\hline CEACAM5 & 1048 & Hs00237075_m1 & GCATCACAGTCTCTGCATCTGGAAC & 27.6 & 0.07 & 100 & .4607 & 0.60 \\
\hline KRT19 & 3880 & Hs00761767_s1 & GCGTCCTGACCGCGTCCGACGGGCT & 34.4 & 0.33 & 100 & .5568 & 1.23 \\
\hline MUC1 & 4582 & Hs00159357_m1 & TAGCCCCTATGAGAAGGTTTCTGCA & 26.4 & 0.02 & 100 & .5466 & 1.16 \\
\hline$E S D(H K)$ & 2098 & Hs00382661_m1 & CTCCGCCACCGTAGAATCGCCTACC & 29.6 & 0.03 & 100 & .3694 & 0.90 \\
\hline$B 2 M(H K)$ & 567 & Hs99999907_m1 & TAAGTGGGATCGAGACATGTAAGCA & 23.8 & 0.03 & 100 & .3694 & 1.11 \\
\hline
\end{tabular}

All genes are expressed in the majority of the endobronchial lining fluid $(E L F)$ samples with median cycle threshold $(C t)$ values between 23 and 39 , and low median absolute deviations $(M A D)$. Paired $t$ test was performed for all lesions identified as non-small cell lung cancer (NSCLC) tumors to identify differentially expressed genes $(P$ value $<.05$; linear median fold change $>2$ ). $q R T$ - $P C R$, quantitative real-time polymerase chain reaction; $I D$, identification; $E S D(H K)$, esterase D (Hong Kong); $B 2 M(H K)$, beta-2-microglobulin (Hong Kong); MMP9, matrix metalloprotinase 9; TWIST1, twist homolog 1 (Drosphila); CEACAM, carcinoembryonic antigen-related cell adhesion molecule; $C D H 1$, cadherin 1, type 1, E-cadherin (epithelial); EGFR, epidermal growth factor receptor; KRT19, keratin 19; $M U C 1$, mucin 1 (cell surface associated).

lung samples. Other genes did not achieve significance level according to expression heterogeneity among all ELF samples (Table 2).

\section{DISCUSSION}

Solitary pulmonary nodules are a frequent incidental finding because of current widespread use of computed tomography in the investigation of respiratory symptoms. However, as imaging techniques improve and more nodules are detected, the optimal management of these nodules remains unclear. Current tests for the diagnosis of solitary pulmonary nodules, with regard to their performance characteristics and complication rates, are far from ideal. Bronchoscopic

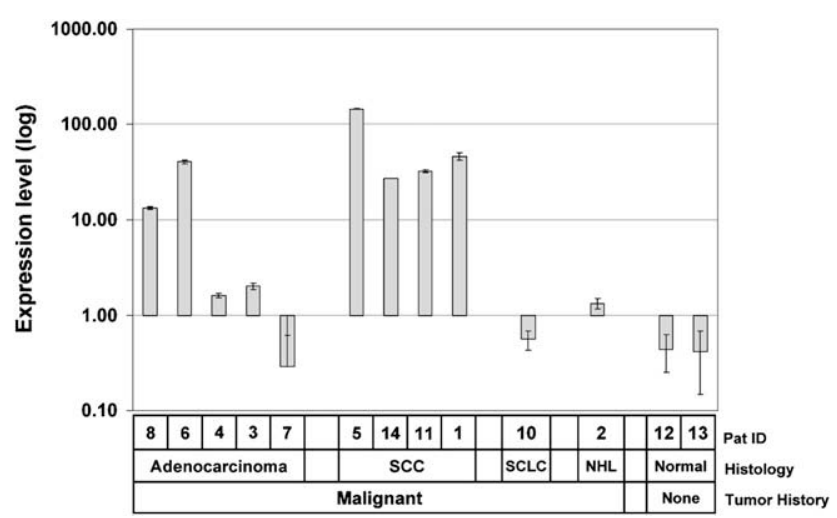

FIGURE 2. Using quantitative real-time polymerase chain reaction, differential expression was observed for MMP9 between endobronchial epithelial lining fluid samples collected by bronchoscopic microsampling next to the lesion and from the contralateral lung of patients with pulmonary nodules that were finally diagnosed to be lung cancer $(P=.0039)$. All expression values were normalized using ESD and B2M as internal control genes. $S C C$, Squamous cell carcinoma; $S C L C$, small cell lung cancer; $N H L$, nonHodgkin lymphoma; Pat $I D$, patient identification. or computed tomography-guided tissue sampling often yields a specific malignant diagnosis but suffers from sampling bias, which dictates additional workup if biopsy results are nondiagnostic in patients with a high pretest probability of malignancy. The associated pneumothorax rate, albeit high, infrequently leads to significant morbidity. ${ }^{1,2}$

The major advantage of the BMS probe used in this study is that it is less invasive than transbronchial biopsy or needle

TABLE 3. The qRT-PCR result for MMP9 indicates upregulation in the ELF lesion of the patients with NSCLC compared with the matched contralateral samples

\begin{tabular}{|c|c|c|c|}
\hline \multirow[b]{2}{*}{ Pt. no. } & \multirow[b]{2}{*}{$\begin{array}{c}\text { Histologic } \\
\text { diagnosis }\end{array}$} & \multicolumn{2}{|c|}{ MMP9 qRT-PCR ELF lesion vs ELF CL } \\
\hline & & $\begin{array}{c}\text { Expression } \\
\text { level }\end{array}$ & Error \\
\hline 1 & SCC & 38.23 & 2.52 \\
\hline 2 & NHL & 1.42 & 0.18 \\
\hline 3 & $\mathrm{AC}$ & 2.36 & 0.17 \\
\hline 4 & $\mathrm{AC}$ & 2.09 & 0.11 \\
\hline 5 & SCC & 116.54 & 1.16 \\
\hline 6 & $\mathrm{AC}$ & 49.75 & 2.41 \\
\hline 7 & $\mathrm{AC}$ & 0.40 & 0.54 \\
\hline 8 & $\mathrm{AC}$ & 17.27 & 0.75 \\
\hline 9 & $\mathrm{AC}$ & N/A & N/A \\
\hline 10 & SCLC & 0.46 & 0.12 \\
\hline 11 & SCC & 60.26 & 1.96 \\
\hline 12 & Benign & 0.57 & 0.21 \\
\hline 13 & Benign & 0.28 & 0.24 \\
\hline 14 & SCC & 16.47 & 0.07 \\
\hline 15 & $\mathrm{AC}$ & N/A & N/A \\
\hline
\end{tabular}

Expression level, Relative quantification between endobronchial lining fluid (ELF lesion and ELF contralaateral lesion $(C L)$ using housekeeping genes esterase D $(E S D)$ and beta-2-microglobulin $(B 2 M)$ for normalization; error, error continuation calculated by median absolute deviation of technical triplicate measurements of each sample. $q R T-P C R$, Quantitative real-time polymerase chain reaction; $M M P 9$, matrix metalloprotinase; $S C C$, squamous cell carcinoma; $N H L$, non-Hodgkin lymphoma; $A C$, adenocarcinoma; $S C L C$, small cell lung cancer; $N / A$, not available. 
aspiration and thus can be applied widely in an outpatient setting. ${ }^{5-9}$ The probe allows quantitative sampling of epithelial ELF from subsegmental bronchi near the nodule during bronchoscopy. Watanabe and colleagues ${ }^{10}$ were the first to evaluate the potential application of that probe in the evaluation of pulmonary nodules. They could demonstrate that there were significantly higher concentrations of cytokeratin 19 and carcinoembryonic antigen (CEA) proteins in ELF next to peripheral lung adenocarcinomas, compared with levels detected in ELF retrieved from contralateral lung of the same subjects and the lungs of individuals who did not have lung cancer. It is intriguing that CYFRA and CEA from ELF samples marked the malignant nodules even when serum levels were not elevated. ${ }^{10}$ To explain this phenomenon, one may hypothesize that markers released from small peripheral malignant tumors of the lung would be diluted away in epithelial ELF to levels indistinguishable from background concentrations. The microsampling probe, however, would soak up small samples of ELF near the peripheral nodule during bronchoscopy. ${ }^{10}$

The results of the present study suggest that measurements of specific tumor-associated genes in ELF samples collected by BMS can detect lung cancer among patients with indeterminate solitary pulmonary nodules. The data indicate that RNA in adequate amounts and quality for further gene expression analysis can be extracted from the majority of ELF samples collected by BMS. This concept may open the way to screen for new biomarkers and to improve the accurate and early detection of lung cancer, potentially eliminating more risky invasive procedures now commonly used to distinguish benign from malignant nodules. In 2 of 15 patients, ELF sample pairs could not be further analyzed. This indicates that improvements of the microsampling procedure, for example, optimization of distance, time, and performance of ELF sampling, are required.

A limited number of genes, potential tumor markers and controls, were analyzed to demonstrate the feasibility of our workflow and to unravel expression changes in ELF samples next to the tumor lesion. We found MMP9 gene expression levels in ELF samples collected next to NSCLC lesions to be in median 12 times higher than levels detected in ELF retrieved from the contralateral lung of the same subjects. Moreover, in the 4 cases of squamous cell carcinoma, $M M P 9$ gene expression was in the range of 50 (median) times higher in the ELF lesion compared with the contralateral site. In contrast, $M M P 9$ expression levels were not elevated in ELF samples collected from patients with benign lesions. Matrix metalloproteinase (MMP)-mediated degradation of the extracellular matrix is a key mechanism in tumor growth and invasion, and $M M P 9$ expression levels were found to be increased in NSCLC tumor tissues. ${ }^{11,12}$ The gene was markedly overexpressed in squamous cell carcinoma compared with adenocarcinoma and normal tissue. ${ }^{13}$ Moreover, increased serum levels of $M M P 9$ were found to be predictive of disease progression in patients with advanced NSCLC. ${ }^{14-17}$ From our preliminary data it may be hypothesized that increased MMP 9 levels detected in ELF sampled next to an NSCLC lesion would derive from macrophages collected alongside the epithelial ELF. In our study, cytospin preparations from microsampling specimens revealed proportions of $50 \%$ to $80 \%$ macrophages among cells collected. It has been shown that tumor-associated macrophages express $M M P 9$ and that $M M P 9$-expressing tumor-associated macrophages play a key role in preparing premetastatic sites for eventual malignant cell growth in a manner dependent on vascular endothelial growth factor receptor-1. ${ }^{18,19}$ Moreover, increased expression of mRNA tissue inhibitor of matrix metalloproteinase-1 in nontumorous surrounding lung tissue of resected NSCLC was demonstrated, suggesting that MMP-induced changes may be detectable in normal lung tissue next to NSCLC lesions. ${ }^{20}$ On the other hand, messenger RNA levels from other genes that were frequently found to be overexpressed in NSCLC tumor tissues, including KRT19, CEACAM3, CEACAM5, EGFR, TWISTI, MUC1, and CDH1, were not found to be concordantly increased in ELF samples collected next to NSCLC lesions compared with ELF retrieved from the contralateral lung of the same subjects or the lungs of patients with benign lesions. One reason for this may be the low proportion of epithelial cells in ELF samples and the impact of noise deriving from a more heterogeneous expression in macrophages and lymphocytes. Thus, classic tumor cell-derived candidate genes may be of limited use when investigating ELF samples on the transcriptional level, indicating the need of novel target genes and a screening approach specific for BMS sampling.

In conclusion, our results show that gene expression analysis of ELF collected by BMS is both feasible and reliable, and measurements of specific tumor-associated genes in ELF samples may be a useful additional diagnostic method in patients with indeterminate pulmonary nodules. Of note, our pilot study did not establish a new standard procedure for the management of patients with indeterminate pulmonary nodules: Larger studies are required to warrant a departure from this novel diagnostic method into clinical routine. Because of the specific characteristics of ELF discussed herein, however, adequate biomarkers or biomarker combinations with the highest predictive value still need to be identified and validated for this particular method in a larger collective.

We thank Mrs Elisabeth Chang Xu and Sabrina Balaguer for their expert technical assistance. The microsampling probes were generously supplied by Olympus Ltd, Tokyo, Japan.

\section{References}

1. Gould MK, Fletcher J, Iannettoni MD, Lynch WR, Midthun DE, Naidich DP, et al. Evaluation of patients with pulmonary nodules: when is it lung cancer? ACCP evidence-based clinical practice guidelines (2nd edition). Chest. 2007; 132:108S-30S. 
2. Wahidi MM, Govert JA, Goudar RK, Gould MK, McCrory DC. Evidence for the treatment of patients with pulmonary nodules: when is it lung cancer?: ACCP evidence-based clinical practice guidelines (2nd edition). Chest. 2007;132: 94S-107S.

3. Hanahan D, Weinberg RA. The hallmarks of cancer. Cell. 2000;100:57-70. Review.

4. Kuner R, Muley T, Meister M, Ruschhaupt M, Buness A, Xu EC, et al. Global gene expression analysis reveals specific patterns of cell junctions in non-small cell lung cancer subtypes. Lung Cancer. 2008;63:32-8.

5. Sasabayashi M, Yamazaki Y, Tsushima K, Hatayama O, Okabe T. Usefulness of bronchoscopic microsampling to detect the pathogenic bacteria of respiratory infection. Chest. 2007;131:474-9.

6. Nakano Y, Tasaka S, Saito F, Yamada W, Shiraishi Y, Ogawa Y, et al. Endothelin-1 level in epithelial lining fluid of patients with acute respiratory distress syndrome. Respirology. 2007;12:740-3.

7. Kipnis E, Guery B, Wiener-Kronish J. Promises and limitations of the bronchoscopic microsampling probe. Chest. 2007;132:1414.

8. Ishizaka A, Watanabe M, Yamashita T, Ogawa Y, Koh H, Hasegawa N, et al. New bronchoscopic microsample probe to measure the biochemical constituents in epithelial lining fluid of patients with acute respiratory distress syndrome. Crit Care Med. 2001;29:896-8

9. Yamazaki K, Ogura S, Ishizaka A, Oh-hara T, Nishimura M. Bronchoscopic microsampling method for measuring drug concentration in epithelial lining fluid. Am J Respir Crit Care Med. 2003;168:1304-7.

10. Watanabe M, Ishizaka A, Ikeda E, Ohashi A, Kobayashi K. Contributions of bronchoscopic microsampling in the supplemental diagnosis of small peripheral lung carcinoma. Ann Thorac Surg. 2003;76:1668-72; discussion 73.

11. Sienel W, Hellers J, Morresi-Hauf A, Lichtinghagen R, Mutschler W, Jochum M, et al. Prognostic impact of matrix metalloproteinase-9 in operable non-small cell lung cancer. Int J Cancer. 2003;103:647-51.
12. Leinonen T, Pirinen R, Bohm J, Johansson R, Ropponen K, Kosma VM. Expression of matrix metalloproteinases 7 and 9 in non-small cell lung cancer. Relation to clinicopathological factors, beta-catenin and prognosis. Lung Cancer. 2006;51: 313-21.

13. Kettunen E, Anttila S, Seppanen JK, Karjalainen A, Edgren H, Lindstrom I, et al Differentially expressed genes in nonsmall cell lung cancer: expression profiling of cancer-related genes in squamous cell lung cancer. Cancer Genet Cytogenet. 2004;149:98-106.

14. Iizasa T, Fujisawa T, Suzuki M, Motohashi S, Yasufuku K, Yasukawa T, et al Elevated levels of circulating plasma matrix metalloproteinase 9 in non-small cell lung cancer patients. Clin Cancer Res. 1999;5:149-53.

15. Ondo K, Sugio K, Yamazaki K, Yamaguchi M, Yano T, Yoshino I, et al. The significance of serum active matrix metalloproteinase-9 in patients with non-small cell lung cancer. Lung Cancer. 2004;46:205-13.

16. Mihaylova Z, Ludovini V, Gregorg V, Floriani I, Pistola L, Toffaneti F, et al Serum level changes of matrix metalloproteinases 2 and 9, vascular endothelial growth factor and epidermal growth factor receptor during platinum-based chemotherapy in advanced non-small cell lung cancer patients. J Buon. 2007;12: 105-11.

17. Di Carlo A, Terracciano D, Mariano A, Macchia V. Matrix metalloproteinase-2 and matrix metalloproteinase-9 type IV collagenases in serum of patients with pleural effusions. Int J Oncol. 2005;26:1363-8.

18. Hiratsuka S, Nakamura K, Iwai S, Murakami M, Itoh T, Kijima H, et al. MMP9 induction by vascular endothelial growth factor receptor-1 is involved in lungspecific metastasis. Cancer Cell. 2002;2:289-300.

19. van Kempen LC, Coussens LM. MMP9 potentiates pulmonary metastasis formation. Cancer Cell. 2002;2:251-2.

20. Safranek J, Holubec L Jr, Topolcan O, Pesta M, Klecka J, Vodicka J, et al. Expression of mRNA MMP-7 and mRNA TIMP-1 in non-small cell lung cancer. Anticancer Res. 2007;27:2953-6. 